\title{
A complexidade da docência: a percepção de estagiários de Pedagogia sobre os desafios para a promoção do bem-estar docente
}

\section{The complexity of teaching: the perception of Pedagogy interns about the challenges for the promotion of teaching well-being}

La complejidad de la enseñanza: la percepción de los pasantes de Pedagogía sobre los desafios para promover el bienestar de los docentes

\author{
Eliane Terezinha Tulio Ferronato ${ }^{1}$ \\ Flavinês Rebolo ${ }^{2}$
}

DOI: http://dx.doi.org/10.20435/serie-estudos.v26i56.1449

\begin{abstract}
Resumo: Este artigo apresenta os desafios da docência nos anos iniciais do Ensino Fundamental, na percepção de seis acadêmicas do curso de Pedagogia, durante o período de Estágio Supervisionado (ES), realizado em cinco escolas municipais de uma cidade do interior de Mato Grosso do Sul (MS). A metodologia, de abordagem qualitativa, utilizou como dados para as análises as narrativas autobiográficas produzidas nos relatórios finais do Estágio Supervisionado. Com objetivo de compreender quais as percepções que as estagiárias tiveram sobre os desafios da profissão docente e se permaneciam motivadas para a docência após a realização do estágio, as narrativas foram analisadas por meio da análise temática de conteúdo, proposta por Fritz Schütze. Constatou-se que, apesar de terem percebido alguns desafios e ou fatores dificultadores do bem-estar docente, como a superlotação e a indisciplina na sala de aula, a complexa relação entre família e escola, a falta de recursos materiais e a inclusão de crianças com deficiências, essas estagiárias continuaram motivadas e determinadas a abraçar a profissão docente.
\end{abstract}

Palavras-chave: estágio supervisionado; narrativas autobiográficas; bem-estar/mal-estar docente.

Abstract: This article presents the challenges of teaching in the early years of the elementary school in the perception of six students from the Pedagogy course, during the period of Supervised

\footnotetext{
${ }^{1}$ Universidade do Estado de Mato Grosso do Sul (UEMS), Dourados, Mato Grosso do Sul, Brasil.

${ }^{2}$ Universidade Católica Dom Bosco (UCDB), Campo Grande, Mato Grosso do Sul, Brasil.
} 
Internship (ES), held in five municipal schools in a city in the interior of Mato Grosso do Sul (MS). The methodology, with a qualitative approach, used autobiographical narratives produced in the final reports of the Supervised Internship as data for analyzes. To understand the perceptions that the interns had about the challenges of the teaching profession and if they remained motivated to teach after the internship, the narratives were analyzed through thematic content analysis, proposed by Fritz Schütze. We found that, despite having perceived some challenges and/or factors that hinder teaching well-being, such as overcrowding and indiscipline in the classroom, the complex relationship between family and school, the lack of material resources, and the inclusion of children with disabilities, these interns remained motivated and determined to embrace the teaching profession.

Keywords: supervised internship; autobiographical narratives; teaching well-being/malaise.

Resumen: Este artículo presenta los desafíos de la enseñanza en los primeros años de la escuela primaria, en la percepción de seis estudiantes del curso de Pedagogía, durante el período de Pasantía Supervisada (ES), realizada en cinco escuelas municipales en una ciudad en el interior de Mato Grosso do Sul (MS). La metodología, con un enfoque cualitativo, utilizó narraciones autobiográficas producidas en los informes finales de la Pasantía Supervisada como datos para los análisis. Para comprender las percepciones que las pasantes tenían sobre los desafíos de la profesión docente y si seguían motivadas para enseñar después de la pasantía, las narraciones se analizaban mediante un análisis de contenido temático, propuesto por Fritz Schütze. Se encontró que, a pesar de haber percibido algunos desafíos y/o factores que obstaculizan el bienestar del maestro, como el hacinamiento y la indisciplina en el aula, la compleja relación entre la familia y la escuela, la falta de recursos materiales y la inclusión de niños con discapacidades, estas pasantes permanecieron motivadas y decididas a abrazar la profesión docente.

Palabras clave: pasantía supervisada; narraciones autobiográficas; bienestar/malestar de los docentes.

\section{INTRODUÇÃO}

No âmbito da formação de professores, o Estágio Supervisionado (ES) é colocado como "um importante componente curricular de indispensável relevância para a formação profissional dos licenciandos" (KRUG et al., 2015), pois se constitui, segundo Pimenta e Lima (2004), como um retrato da prática docente, no qual o futuro professor (estagiário) tem muito a dizer, a ensinar, expressando sua realidade, a de seus colegas de profissão e de seus alunos, que, no mesmo tempo histórico, vivenciam os mesmos desafios e as mesmas crises na escola e na universidade.

A pesquisa apresentada neste artigo se desenvolveu a partir da compreensão de que o estágio é um processo de fundamental importância para o início da carreira do professor por vários motivos, como explica Jesus (2007), afirmando que é no Estágio Supervisionado que 
Ocorrem as experiências profissionais mais marcantes; é um dos poucos períodos, do percurso profissional, em que se tem acompanhamento e orientação de um professor mais experiente bem como é nessa fase em que os futuros professores estão mais sensibilizados e receptivos para aprender os imperativos da profissão. (JESUS, 2007, p. 48).

A função do estágio é preparar o estagiário para compreender a escola em sua realidade multifacetada e transformar os seus sentimentos (da escola) em aprendizagem, desmistificando certos preconceitos, estereótipos e ideias romantizadas sobre a escola e o ser professor. Para tanto, o estagiário deveria entrar na escola com o olhar de um pesquisador, para observar, refletir, analisar e compreender a realidade escolar.

Porém, para que esse olhar de pesquisador aconteça durante o estágio, segundo Jesus (2007), é necessário haver um apoio significativo, tanto por parte do professor de estágio como por parte da escola e dos seus agentes, pois, do contrário, o estagiário pode "perceber o processo de ensino-aprendizagem como fonte de stress profissional, podendo atingir um estado de exaustão emocional" (JESUS, 2007, p. 49) e desejo de abandonar a profissão.

É neste período que ocorre a transição da formação inicial para a prática profissional, ou seja, a passagem do estudante para professor. É também um período que pode auxiliar o professor recém-formado a superar o "choque com a realidade", que, segundo Veenman (1984), indica o "colapso dos ideais missionários formados durante o treinamento do professor sobre a realidade árdua e dura da vida diária em sala de aula" (VEENMAN, 1984, p. 144). Ainda para esse autor, apesar de o professor iniciante já conhecer o contexto no qual vai trabalhar, pois frequentou esse ambiente escolar desde a mais tenra idade (no papel de estudante), ao chegar no espaço escolar, no papel de professor, vai se deparar com outra realidade, com inúmeras dificuldades que não havia pensado e ou percebido no papel de aluno. Portanto o estágio tem função fundamental para auxiliar na apreensão dessa realidade com a qual o futuro professor vai se deparar.

Considerando a relevância do Estágio Supervisionado para a formação de professores, apresentam-se, a seguir, os resultados de uma pesquisa que analisou as narrativas autobiográficas produzidas por seis estagiárias, no relatório final da disciplina de Estágio Supervisionado II, de um curso presencial noturno de Pedagogia, em uma universidade pública do interior de Mato Grosso do Sul. As 
análises foram conduzidas por meio da análise temática de conteúdo, conforme proposta de Fritz Schütze (2007), e tiveram por objetivo identificar as percepções dessas estagiárias a respeito da complexidade e dos desafios do trabalho do professor, bem como sobre os fatores que podem propiciar bem-estar e/ou mal-estar docente. Cabe destacar que a escolha dessas seis participantes se deu por elas terem sido aprovadas em um concurso público para professores de uma rede municipal de ensino, logo após a conclusão do curso de Pedagogia.

Espera-se, com este estudo, ampliar um pouco a compreensão da complexidade do que é tornar-se professor e a importância do Estágio Supervisionado, bem como trazer contribuições para a formação inicial de professores.

\section{AS NARRATIVAS AUTOBIOGRÁFICAS E AS PARTICIPANTES DA PESQUISA}

A pesquisa é de abordagem qualitativa, pois está interessada nas percepções, motivações e experiências das acadêmicas, o que torna fundamental a aproximação do pesquisador com as participantes da pesquisa. Nesta abordagem, segundo Monteiro (1998), os "pesquisadores estão interessados no entendimento do comportamento sob a perspectiva daqueles que o manifestam, compreendendo o comportamento em seu processo e conferindo importância secundária a causas externas" (MONTEIRO, 1998, p. 7), o que atende aos objetivos deste estudo.

Os dados analisados se constituíram dos relatórios de estágio elaborados pelos acadêmicos no final do período de estágio. Nestes relatórios, são narradas as experiências mais significativas do estágio; as impressões da escola, dos professores, da gestão, coordenação e dos alunos; a importância do estágio; e a contribuição desse estágio para a carreira docente, por meio de narrativas autobiográficas. Esse tipo de narrativa foi escolhido, pois, juntamente de Nóvoa (2009), concorda-se que "o registro escrito, tanto das vivências pessoais como das práticas profissionais, é essencial para que cada um adquira uma maior consciência de seu trabalho e da sua identidade como professor" (NÓVOA, 2009, p. 182).

Assim, com o objetivo de proporcionar atividades que propiciassem o refletir sobre si e sobre as práticas docentes, foi solicitado aos estagiários que produzissem narrativas autobiográficas durante a escrita do relatório de estágio. Os acadêmicos foram orientados pelas professoras do estágio a registrar diariamente as vivências em sala de aula, os sentimentos e as inquietações que, de outra forma, poderiam 
ser esquecidos na dinâmica do tempo, permitindo um olhar mais minucioso para a escrita do relatório final de estágio.

Dos 25 relatórios produzidos pela turma do último semestre/2018 do Curso de Pedagogia, foram selecionados seis para a realização desta pesquisa. Os seis relatórios são todos de estagiárias do sexo feminino, com idade entre 25 e 27 anos, com pouca experiência na docência (Quadro 1), e o critério de seleção foi o fato de essas seis acadêmicas, após a conclusão do curso, terem sido aprovadas em concurso público da rede municipal de ensino.

Quadro 1 - Caracterização das participantes da pesquisa

\begin{tabular}{|c|c|c|c|}
\hline $\begin{array}{c}\text { Acadêmicas/ } \\
\text { estagiárias }^{3}\end{array}$ & Idade & $\begin{array}{c}\text { Profissão que exerciam, } \\
\text { enquanto acadêmicas }\end{array}$ & $\begin{array}{c}\text { Experiência como docentes } \\
\text { anterior ao estágio } \\
\text { (em 2018) }\end{array}$ \\
\hline FRIDA & 23 & Auxiliar de escritório & Nenhuma \\
\hline EMILIA & 42 & Dona de casa & $\begin{array}{c}\text { Projeto de leitura em uma escola } \\
\text { municipal, durante um ano }\end{array}$ \\
\hline MARIE & 22 & Agente de saúde & Nenhuma \\
\hline SABINE & 25 & Assistente de Educação & $\begin{array}{c}\text { Assistente de uma Instituição de } \\
\text { Infantil }\end{array}$ \\
\hline TARSILA & 40 & Dona de casaão Infantil por quatro anos & $\begin{array}{c}\text { Professora substituta em escolas } \\
\text { municipais por } 2 \text { anos }\end{array}$ \\
\hline MARIA & 25 & Estudante & Bolsista PIBID ${ }^{4}$, durante três anos \\
\hline
\end{tabular}

Fonte: Elaborado pelas autoras a partir dos relatórios de estágio.

Pelo Quadro 1, percebe-se que Frida e Marie não tiveram nenhuma experiência com sala de aula; Emília e Maria participaram de projetos oferecidos pela universidade; Tarsila realizou algumas substituições nos anos iniciais; e Sabine tem experiência com a Educação Infantil, mas nenhum contato com os anos iniciais do Ensino Fundamental. Portanto, para quase todas elas, o estágio se constituiu como o primeiro contato com a sala de aula no papel de docente.

\footnotetext{
3 Para resguardar a identidade das participantes, além de seus nomes não serem informados na pesquisa, elas serão identificadas pelos pseudônimos que elas mesmas escolheram.

${ }^{4}$ Programa Institucional de Bolsas de Iniciação à Docência (PIBID).
} 


\section{FATORES DIFICULTADORES DO BEM-ESTAR DOCENTE PERCEBIDOS PELAS ESTAGIÁRIAS}

A partir das análises dos relatórios de estágio, foi possível observar que as acadêmicas identificaram alguns fatores que podem ser considerados como geradores de mal-estar docente ou, como elas registram em suas narrativas, "os maiores desafios ou 'nós' que o professor tem que desatar, para que o bem-estar docente se efetive".

Os maiores fatores de mal-estar que o professor enfrenta na profissão docente, segundo Jesus (1998), podem ser de várias ordens: a) pessoais e/ou relacionados à vida privada (como a personalidade do professor, instabilidade familiar, relações sociais, ocupação dos tempos livres, entre outros); b) podem estar ligados às relações estabelecidas com os alunos (indisciplina e o desinteresse dos alunos etc.); c) relações com os colegas (falta de cooperação, por exemplo); d) relações estabelecidas com os encarregados de educação (falta de participação na vida escolar dos filhos); e) processo de ensino-aprendizagem (preparação das aulas, avaliação dos alunos); f) condições de trabalho (sobrecarga de tarefas, falta de recursos materiais); e g) contexto socioeducativo (colocação, falta de reconhecimento social, indefinição do papel do profissional) (JESUS, 1998, p. 62).

Com as análises, foram identificados os fatores dificultadores do bem-estar docente, citados de forma mais recorrente nos relatórios de estágio, que são: a relação entre a família dos estudantes e a escola; a falta de recursos materiais pedagógicos; o grande número de crianças por sala de aula/turma, a indisciplina e a dificuldade da inclusão.

\section{A RELAÇÃO ENTRE A FAMÍLIA E A ESCOLA E O BEM-ESTAR/MAL-ESTAR DO PROFESSOR}

Um dos dilemas atuais da educação é a difícil relação entre a família e a escola, observada por uma das estagiárias participantes e considerada, por ela, como um dos maiores desafios que terá de enfrentar quando assumir uma sala de aula como professora:

[...] como agir, dentro desta realidade, onde a falta de interesse da família é gritante e a culpa do fracasso escolar acaba recaindo sobre o professor e a instituição em geral, onde professor passa a responsabilidade à família e a 
A complexidade da docência: a percepção de estagiários de Pedagogia sobre os desafios para a promoção do bem-estar docente

família ao professor e isto vêm visivelmente refletindo na vida do educando. Então fica um ponto de interrogação: Como fazer? O que fazer? Assunto este que vem me angustiando, quando realmente eu tiver que assumir uma sala. (Emilia, 2018).

Porém, para compreender a complexidade dessa relação, é preciso entender que, historicamente, no Brasil, a própria constituição da escola, como uma instituição essencial e necessária para "civilizar e trazer progresso" à sociedade brasileira, baseada no ideário republicano, acabou por afastar as famílias da escola. Segundo Castro e Ragattieri (2010, p. 21), "a importância crescente da escola primária teve como contraponto a desqualificação das famílias para a tarefa de oferecer a instrução elementar, progressivamente delegada à instituição escolar, cujos profissionais estariam tecnicamente habilitados para isso". Assim, a educação dos filhos se torna uma tarefa do Estado e as famílias, gradativamente, são afastadas da escola. É a escola (o Estado) que passa a orientar os hábitos e comportamentos de higiene, de saúde e de educação das crianças.

Outra importante mudança que influenciou esta relação está na configuração atual das famílias, determinada por diversos fatores. As mulheres passaram a trabalhar fora de casa, deixando ao encargo da escola muitas funções que eram exclusivamente das famílias. Hoje, também, muitas famílias são compostas por mãe ou pai solteiro, que trabalham para garantir o sustento e não conseguem tempo disponível para acompanhar a vida escolar dos filhos.

Esses fatores, entre outros que alteraram a configuração das famílias e das escolas, segundo Jesus (2004, p. 83), contribuíram para que aumentassem as responsabilidades dos professores e suas funções. Para o autor, a família passa a delegar para o professor a função de educar seus filhos. E foi exatamente essa a percepção que Emília teve, durante a realização do estágio.

Acrescento uma observação e opinião minha, em relação a educação dos educandos, acredito que o baixo desenvolvimento dos alunos, está relacionado a estrutura familiar, que acaba refletindo em sala de aula com a falta de respeito para com o professor e colegas e até mesmo com os conteúdos curricular. (Emília, 2018).

Emília comenta ainda que, após ter observado o livro de presença dos pais nas reuniões da escola, percebeu que apenas alguns pais comparecem à instituição e, mesmo assim, apenas às reuniões para entrega de notas. 
Como podem exigir do professor uma educação de qualidade, se eles (os pais e ou responsáveis) não se preocupam, não demostram interesse pela educação de seus filhos? (Emília, 2018).

Para Marchesi (2008), a maioria das famílias vive situações distintas e, às vezes, adversas, em que "o trabalho dos dois membros do casal, a pressão laboral e a rigidez nos horários reduzem as possibilidades de dar maior dedicação aos filhos e de participar nas atividades escolares" (MARCHESI, 2008, p. 18). E isso traz pouca expectativa sobre a educação das crianças pela família, bem como distancia a família da escola, como pode ser constatado, também, na narrativa de Marie:

A professora comentou que os pais estão sempre cobrando da escola e dela, para que seus filhos tenham a melhor educação. Porém, ressalta essa professora, que em contrapartida sempre evidencia a importância das tarefas de casa, mas quando mandado não tem retorno eficaz, apenas alguns dos alunos fazem. (Marie, 2018).

Marie também percebeu que os pais estão delegando ao professor tarefas que eram da família, como o respeito e o comportamento:

Muitos pais estão vinculando a educação da aprendizagem, com a educação de respeito, comportamento e disciplina. Infelizmente o professor passa a maior parte do tempo tratando de um assunto que deveria ser proveniente da família, acaba se desgastando e atrapalhando seu desempenho na realização das demais aprendizagens. (Marie, 2018).

Essa angústia que afeta Emília e Marie, e que pode ser um fator gerador de mal-estar docente, não é um sentimento incomum entre os professores. Marchesi (2008) explicita que a maioria dos professores considera que um maior envolvimento das famílias na educação de seus filhos seria uma das principais condições para melhorar a qualidade do ensino e, consequentemente, o bem-estar docente.

Oliveira e Marinho-Araújo (2010), ao analisarem a história da relação que se estabeleceu entre escola e família ao longo do tempo, relatam que em certos momentos essa relação foi caracterizada em função de determinantes sociais, e, em outros, em função de aspectos psicológicos da família e do próprio sujeito: "[...] esta relação sempre esteve marcada por movimentos de culpabilização de uma das partes envolvidas, pela ausência de responsabilização compartilhada de 
A complexidade da docência: a percepção de estagiários de Pedagogia sobre os desafios para a promoção do bem-estar docente

todos os envolvidos e pela forte ênfase em situações-problema que ocorrem no contexto escolar" (OLIVEIRA; MARINHO-ARAUJO, 2010, p. 103).

Castro e Ragattieri (2010) relatam também a importância da relação entre escola e família para a aprendizagem das crianças e dos adolescentes e as "armadilhas" que podem ser construídas a partir da culpabilização da família pelos professores ou vice-versa. Dizem as autoras:

Dos professores, ouvíamos: "os pais dos alunos que mais precisam de ajuda são sempre os mais difíceis de trazer até a escola". Dos pais desses alunos que mais precisam, ouvíamos: "nós, que mais precisamos de ajuda, somos os mais cobrados pelas escolas". E uns não escutam os outros. Neste jogo de busca de culpados, a assimetria de poder entre profissionais da educação e familiares costuma pesar a favor dos educadores, principalmente quando temos, de um lado, os detentores de um saber técnico e, de outro, sujeitos de uma cultura iletrada. Novamente, se essas diferenças são convertidas em desigualdade, a distância entre alguns tipos de famílias e as escolas que seus filhos frequentam se amplia. Podemos dizer que usar a assimetria de poder para transferir da escola para o aluno e sua família o peso do fracasso transforma pais, mães, professores, diretores e alunos em antagonistas, afastando estes últimos da garantia de seus direitos educacionais. É uma armadilha completa. (CASTRO; RAGATTIERI, 2010, p. 31).

Já há algum tempo que os professores culpam os pais e os pais culpam os professores pelo fracasso escolar dos alunos. No entanto, concorda-se com Castro e Ragattieri (2010) que buscar culpados não é a melhor forma de resolver o problema. Seria necessário aproximar a escola e a família, como afirma Marchesi (2008), e essa é uma das competências que o professor deve adquirir, para que seja possível o bem-estar docente: a capacidade de colaborar e ter a colaboração e o envolvimento das famílias no contexto escolar. "É uma competência necessária que praticamente não tem recebido atenção" (MARCHESI, 2008, p. 86).

Durante a formação inicial dos professores, essa competência precisaria ser desenvolvida e, segundo Marchesi (2008), é preciso que os professores tenham paciência e tempo, bem como "sensibilidade para gerar confiança, estar atento aos problemas, saber escutar, estar disposto a admitir suas propostas e dispor das estratégias adequadas para criar um clima de colaboração" (MARCHESI, 2008, p. 86). Os professores, apesar de todos os desafios que enfrentam, ao compreenderem a situação das famílias, suas dificuldades, suas carências e também as suas possibilidades, terão maiores possibilidades de aproximar a família e a escola. 
Enfim, é necessário que se tenha claro que ambas as partes, tanto a escola como a família, apesar de serem instituições diferentes e com objetivos distintos, "compartilham a importante tarefa de preparar crianças e adolescentes para a inserção na sociedade, a qual deve ter uma característica crítica, participativa e produtiva" (OLIVEIRA; MARINHO-ARAÚJO, 2010, p. 107).

E esse é também um dos papéis da formação inicial e do estágio supervisionado: preparar o futuro professor para essa tarefa complexa que é o relacionamento entre escola e família. O professor iniciante precisa compreender que, para que as duas instituições possam construir uma parceria que contribua de forma efetiva para a aprendizagem e o desenvolvimento dos alunos, é necessário romper com as posturas defensivas e acusativas que permeiam essa relação nos dias atuais, como se cada um buscasse se justificar e encontrar razões para a desarmonia e o mal-estar docente que caracterizam tal relação. Assim, o bem-estar docente, discente e, por que não, o familiar perpassam por essas questões.

\section{A FALTA DE RECURSOS PEDAGÓGICOS}

A falta de recursos materiais é apontada por Esteve (1999) como indicativo do mal-estar docente e está presente em muitas pesquisas relacionadas ao tema, inclusive nos sistemas educacionais de países desenvolvidos. Uma pesquisa realizada pela Organização Internacional do Trabalho, no começo da década de 1990, explicita que não é incomum o professor ter a ilusão de uma renovação didático-pedagógica e ver o seu trabalho limitado pela falta de material didático ou de recursos para adquiri-los (ESTEVE, 1999). Apesar de essa pesquisa ter sido desenvolvida no final da década de 1990, ela continua muito atual, como se pode notar na narrativa de Sabine:

Observando as aulas vimos que a utilização do quadro negro é constante e as crianças tem que copiar o tempo todo. Perguntei a professora, sobre outras formas de ensinar continhas para as crianças, talvez por meio de material dourado? Ela me respondeu que já cansou de reivindicar materiais para trabalhar em sala de aula. A escola não tem recursos para adquirir os materiais necessários. (Sabine, 2018).

Esteve (1999) afirma que não só a falta do material como também o prolongamento da espera por esse material, que às vezes nunca chega, podem prejudicar

o bom desempenho do professor. Quando essa situação se prolonga em médio 
e longo prazo, poderá produzir uma reação de inibição no professor, que acaba aceitando a velha rotina escolar, depois de perder a ilusão de uma mudança em sua prática docente que, além de exigir-Ihe maior esforço e dedicação, implica a utilização de novos recursos dos quais ele não dispõe (ESTEVE, 1999, p. 48).

Ao tratarem sobre a infraestrutura das escolas públicas brasileiras, Batista e Odelius (1999) comentam que estas têm recursos mínimos de funcionamento, condições ambientais (barulho, conservação do prédio, condições dos banheiros, umidade, poeira, iluminação) razoáveis e se caracterizam por terem condições de trabalho ruins. Jesus (2004) explica que, para a realização de um trabalho de qualidade, é necessário fornecer aos professores condições de trabalho que permitam concretizar a sua motivação e competência profissional. Nas palavras do autor:

São necessários melhores equipamentos, nomeadamente, meios audiovisuais e informáticos, bem como uma melhoria dos espaços físicos, no sentido de tornar as escolas locais mais agradáveis, do ponto de vista da arquitetura e da decoração, contribuindo para a diminuição da agressividade e do stress, não apenas dos professores, mas também dos alunos. (JESUS, 2004, p. 88).

É importante frisar que essa falta de recursos, de materiais, não é novidade dos dias atuais, pois já aparecia nas pesquisas, desde a década de 1970, segundo Esteve (1999), como um dos componentes primordiais para o mal-estar docente. A sociedade contemporânea espera dos professores uma renovação metodológica, e os sistemas de ensino reforçam a necessidade de metodologias inovadoras, porém não fornecem condições nem os recursos necessários para que os professores promovam as mudanças necessárias.

Este descaso, essa série de problemas relacionados à infraestrutura, ao espaço físico da escola, à falta de manutenção, à ausência de materiais e recursos pedagógicos, impacta a qualidade da educação e o bem-estar dos professores, motivando muitos deles a cogitarem a possibilidade de desistir da profissão, como podemos observar por um dos comentários que Emília faz:

Em conversa com a professora pude analisar que está desmotivada com a profissão, já que há 25 anos está no magistério e sempre que tentou inovar em sala de aula, a resposta foi sempre a mesma, a escola não tem recursos para adquirir os materiais necessários. (Emilia, 2018).

Muitas vezes, o professor, para concretizar o planejamento criativo, diferenciado e mais personalizado (para além do quadro de giz e do livro didático), 
adquire os materiais necessários com o seu salário. Jesus (2007, p. 27) comenta que "aumentou-se as responsabilidades dos professores e não houve uma meIhoria efetiva dos recursos materiais e das condições de trabalho".

Assim, a formação inicial e o estágio supervisionado também têm a função de discutir as condições de trabalho, o que inclui, entre outros aspectos, materiais pedagógicos adequados. O futuro professor precisa, no período de estágio, conhecer e refletir sobre essa realidade, buscando caminhos para superar os vários desafios que encontrará ao exercer a docência.

\section{A INDISCIPLINA E A SUPERLOTAÇÃO NAS SALAS DE AULA}

Os professores compõem o centro de um sistema educacional que envolve múltiplos fatores, acumulando responsabilidades e funções que não tinham no passado. Na organização do ensino, o professor debate-se com "dificuldades em organizar o processo ensino aprendizagem" para um "excessivo de alunos" (NÓVOA, 1995, p. 157). É necessário dar aos professores condições de trabalho que possam permitir concretizar a sua competência profissional e realizar um trabalho de qualidade.

Neste sentido, é importante a diminuição do número de alunos por turma, para que o professor possa construir uma relação mais personalizada com os alunos e para a realização de um trabalho de qualidade. Dessa forma, a superlotação nas salas de aula torna ainda mais difícil as relações interpessoais entre professor/ aluno e também entre aluno/aluno. Essas dificuldades foram percebidas por todas as estagiárias, e destacamos a fala de Frida:

O problema é o espaço, isso em todas as salas, são muitos alunos para pouco espaço e por isso, apesar de ter ar-condicionado, a sala é muito quente e abafada, a irritação e o desconforto por parte dos alunos e até mesmo da professora são visíveis e constantes. (Frida, 2018).

Maria comenta que, por conta da superlotação nas salas de aula, a indisciplina acontece quase de forma natural, porque

São muitas crianças na sala de aula, a professora não dá conta de dar atenção a todas. Algumas crianças terminam rapidamente e levam o caderno para a professora corrigir, enquanto outras não saem da primeira atividade, se a professora resolver esperar que todas terminem, os que já terminaram fazem bagunça, conversam, brigam, e se a professora começar a correção 
A complexidade da docência: a percepção de estagiários de Pedagogia sobre os desafios para a promoção do bem-estar docente

coletiva na lousa, muitas das crianças não acompanham e algumas nem conseguem terminar de copiar, penso que esse é um dos maiores desafios dos professores. (Maria, 2018).

Essa dificuldade de os professores atenderem a todas as crianças, por conta da superlotação, é evidenciada por Maria e Emília que, ao analisarem o Projeto Pedagógico da escola, comentam que o que está estabelecido neste documento é:

O número máximo de educando por classe e ano será de acordo com a capacidade da sala, devendo sempre ser respeitado a metragem de 1,50 $\mathrm{m}^{2}$ por educando na Educação Infantil e $1,30 \mathrm{~m}^{2}$ por educando no Ensino Fundamental, conforme estabelecidos nesta Proposta Pedagógica. Assim, qualquer que seja a capacidade física da sala de aula, o número máximo de educando não poderá ultrapassar ao disposto nesta Proposta Pedagógica e 'quando houver educando com necessidades educacionais especiais matriculados, a Unidade Escolar observará o quantitativo máximo de 15 (quinze) educando na Educação Infantil, 20 (vinte) nos Anos Iniciais do Ensino Fundamental e, 25 (vinte cincos) nos anos finais do Ensino Fundamental'. (ESCOLA MUNICIPAL IRMÃ DE LIMA MATTOS [EMILM], 2016, p. 36).

Porém, na observação que fizeram na escola, verificaram que essas regras não são cumpridas. Maria verificou que a quantidade de crianças nas salas de aula é bem maior:

O que mais me chamou atenção foi o espaço muito pequeno da sala do 3 ano, para atender 38 alunos, sendo que no PPP da escola consta que séries iniciais não podem ultrapassar 25 alunos [...] os alunos da primeira fila ficam meio metro do quadro dificultando a visualização dos conteúdos passados no quadro e a professora não tem como ir atender as crianças que sentam no fundo da sala. (Maria, 2018).

Embora o número excessivo de alunos por turma não seja o único determinante da indisciplina, pode-se supor que em classes superlotadas ela ocorrerá mais facilmente. Segundo Jesus (2007), a superlotação em sala de aula tem como um dos resultados mais evidentes a indisciplina, e esta se dá da seguinte forma:

A indisciplina dos alunos integra todos os comportamentos e atitudes que estes apresentam como perturbadoras e inviabilizadoras do trabalho que o professor pretende realizar. Neste sentido, a indisciplina é um conceito de uma grande amplitude, tornando-se difícil encontrar consenso entre os professores no que diz respeito aos comportamentos que devem ser integrados neste conceito. (JESUS, 2007, p. 31). 
Ainda quanto à indisciplina, Nóvoa (1995, p. 177) comenta que "presentemente observamos que o aluno pode permitir-se, com bastante impunidade, diversas agressões verbais, físicas e psicológicas aos professores ou aos colegas", e estes comportamentos estarão mais facilitados em grupos maiores de alunos.

Jesus (2007) alerta que a indisciplina é causa principal de "mal-estar porque acaba por inviabilizar o planejamento das aulas e a qualidade do processo ensino - aprendizagem que o professor pretende atingir" (JESUS, 2007). Tarsila relata a angústia que sentiu ao presenciar salas de aula pequenas com crianças muito agitadas:

Na observação das aulas, como passei em várias salas do Ensino Fundamental, o que me causou muita angústia foi de como as crianças menores do primeiro e segundo ano, estão muito agitadas em comparação aos maiores, a falta de respeito em relação aos professores, o não cumprimento de ordens, que em certos momentos faz com que o professor fique sem ter o que fazer, considerando que as salas são pequenas e são mais de trinta alunos vi aqueles professores estonteados, sem ter meios de como controlar a sala. (Tarsila, 2018).

Portanto um dos obstáculos ao desenvolvimento profissional e fator de mal-estar docente está na quantidade excessiva de alunos por sala de aula, o que dificulta a atenção à diversidade. O professor que trabalha em uma sala numerosa não tem possibilidade de conhecer bem todos os alunos, adaptar-se às suas especificidades, refletir sobre a qualidade das suas práticas. A superlotação em face da dimensão da escola torna ainda mais difíceis as relações interpessoais (GUERRA, 2000).

O trabalho docente exige uma grande diversidade de funções (ensinar, orientar o estudo, ajudar individualmente os alunos, regular as relações, preparar materiais, saber avaliar, organizar espaços e atividades etc.), funções essas que são afetadas diretamente pelo número de alunos que estão sob a responsabilidade do professor.

Para superar essa condição-limite para a atuação do professor, a instituição precisa ter criatividade e capacidade para se autoconhecer a fim de buscar soluções para esse problema que afeta diretamente os fins da escola, que é o aprendizado do aluno, e para evitar que isso traga ao professor características do "mal-estar docente". Sinaliza Jesus (2007, p. 31): "É importante a análise deste tema na actualidade, pois, de acordo, com o resultado obtido em diversas investigações, 
a indisciplina dos alunos constitui o principal factor de stress para muitos professores". Esteve (1999) também assinala os problemas de indisciplina como um dos mais percebidos, principalmente pelos professores iniciantes.

Assim, a indisciplina e as salas de aulas superlotadas são temas relevantes que devem ser foco de investigação e de análise crítica na formação inicial/estágio, para que o futuro professor compreenda a realidade escolar.

\section{AS DIFICULDADES DA EDUCAÇÃO INCLUSIVA}

A inclusão também foi percebida como um dos desafios que os professores enfrentam na escola contemporânea. Sobre esse aspecto, Frida faz a seguinte anotação em seu relatório de estágio, após observar a professora:

A professora, se mostra "perdida", pois além de ter que alfabetizar e "controlar" 20 crianças de cinco a seis anos de idade, passa o tempo todo tentando fazer a criança com hiperatividade ficar dentro da sala de aula e tentando incluir a criança com microcefalia. Uma missão impossível. (Frida, 2018).

A educação inclusiva deve ser pensada a partir do pressuposto de que a educação é um direito humano básico e fundamental para uma sociedade mais justa (SILVA, 2011). O princípio orientador da ideia de educação inclusiva começa a se concretizar no ano de 1994, por meio da Declaração de Salamanca, que consiste na afirmação de que todas as escolas devem ajustar-se a todas as crianças, independentemente das suas condições físicas, sociais, linguísticas, entre outras. Tal condição provoca nos sistemas escolares uma série de desafios, uma vez que estes terão de encontrar formas de educar com sucesso todas as crianças, inclusive as que apresentam incapacidades graves.

Para Silva (2011), inclusão não se refere apenas à partilha de um mesmo espaço físico, e, embora todos concordem que a escola deva ser um lugar que proporcione aprendizagens significativas a todos os alunos, na prática, esse aspecto tem gerado diversas polêmicas e questionamentos por parte dos professores. Os professores se queixam da falta de capacitação para trabalhar com crianças com necessidades educacionais especiais, falta de materiais educativos apropriados e, principalmente, falta de apoio e recursos no atendimento pedagógico em classes comuns.

Nesse sentido, pode-se dizer que a educação inclusiva, um direito conquistado pelos movimentos sociais que lutam em favor dos direitos das pessoas, da 
maneira como tem sido implantada nas escolas, torna-se um dos fatores que contribuem para aumentar a incidência do mal-estar docente. E foi esse aspecto que Frida constatou como uma das maiores dificuldades no trabalho do professor.

Frida descreve que se sentiu impactada e assustada ao verificar que, em quase todas as salas em que fez a observação, havia pelo menos uma criança com deficiência e algumas contavam com professores de apoio e outras não:

No primeiro dia observamos o primeiro ano $B$, a sala tem 22 alunos em fase de alfabetização, nesta sala tem uma criança com laudo de microcefalia, que segundo informações da professora, as dificuldades de aprendizagem descritas no laudo não dão direito à professor de apoio. As atividades diferenciadas são realizadas pela professora regente durante sua hora atividade, tem também uma criança que apresenta hiperatividade, necessitando de um atendimento individual e um aluno que apresenta agressividade e falta de concentração, mas com nenhum respaldo por parte dos pais em procurar ajuda. (Frida, 2018).

Ao observar outra sala de aula, comenta:

No terceiro dia observamos a sala do terceiro ano, a sala tem 26 alunos, nesta sala tem um menino cadeirante o Heitor, com laudo de paralisia, segundo a professora conseguiu um professor de apoio recentemente, antes a professora dividia a atenção com os alunos e com ele. (Frida, 2018).

[...] em uma sala com 38 alunos, tem uma criança com laudo de dificuldade de aprendizagem com possivel comprometimento em seu desenvolvimento cognitivo e uma aluna com baixa visão que senta na primeira fila. (Frida, 2018).

Frida confessa que, para definir em qual sala de aula realizaria a etapa da docência, durante o período do estágio supervisionado, escolheu uma sala que não houvesse nenhuma criança com deficiência, pois acreditava que não daria conta de uma sala de aula superlotada e ainda crianças com deficiência.

Mantoan (2003, p. 76) comenta que "a maioria dos professores tem uma visão funcional do ensino e tudo que ameaça romper o esquema de trabalho prático que aprenderam a aplicar em suas salas de aula é inicialmente rejeitado". O aluno com deficiência representa o novo, o desconhecido que, inesperadamente, invade a sala de aula alterando os processos de ensino e aprendizagem que foram apreendidos na formação inicial e, quiçá, antes mesmo dela.

Segundo Silva (2011), para que aconteça uma educação inclusiva, é necessário pensar em novas práticas docentes que possam ser trabalhadas na 
formação continuada. No entanto o autor afirma também que não é somente por meio de uma mudança de atitude do professor que isso acontecerá. Nem por boa vontade dos profissionais da educação, apesar de reconhecer, entretanto, que essa predisposição é inegavelmente importante.

É necessário que os professores tenham os recursos, os materiais necessários, assim como a colaboração de toda a sociedade para que a educação realmente se efetive como inclusiva. E, para Mantoan (2003, p. 45), “Daí a necessidade de se formarem grupos de estudos nas escolas, para a discussão e a compreensão dos problemas educacionais, à luz do conhecimento científico e interdisciplinarmente". Ou seja, os professores precisam unir as forças, discutir ideias, buscar alternativas que permitam entrar em um novo século com perspectivas mais otimistas em relação às respostas educativas de uma escola para todos e para que se efetive o bem-estar docente.

\section{IMPRESSÕES SOBRE O ESTÁGIO E OS ASPECTOS PROMOTORES DO BEM-ESTAR DOCENTE}

O estágio é um momento decisivo na formação de professores, no qual o estagiário terá a oportunidade de efetuar a ligação entre a teoria e prática. Para Rabelo (2019, p. 183), o estágio "é o momento de confrontação com a realidade, muitas vezes acontecendo verdadeiros choques de realidade que podem ser motivadores ou desanimadores dependendo da forma como estes forem resolvidos". E alguns aspectos, como a forma como o estagiário se insere na escola, a forma como é recebido e acolhido na escola e como ele "percebe" a escola, por exemplo, podem tornar o estágio um momento decisivo para a desistência ou a continuidade na profissão.

Analisando as narrativas das estagiárias participantes desta pesquisa, podemos perceber o entusiasmo de algumas. Marie, por exemplo, revela uma expectativa enorme em abraçar a carreira, pois ela sempre sonhou em ser professora, mas ainda não havia se confrontado com o "chão da escola"; todavia o estágio supervisionado se mostrou uma experiência recompensadora:

A experiência de viver a docência foi maravilhosa, amei a experiência de ser professora e ser reconhecida como tal, foi um prazer elaborar as aulas, não vi nada como obrigação e sim como algo que me sentia bem. (Marie, 2018). 
Frida, Emília e Tarsila comentam que essa etapa do estágio foi uma experiência importante, enriquecedora e que auxiliou em várias reflexões sobre a profissão docente:

Foi uma etapa privilegiada de aprendizagem, pois, além de nos proporcionar uma visão da realidade e experiência vivida se tornou extremamente importante e enriquecedora para a nossa formação acadêmica. (Frida, 2018).

O Estágio foi muito enriquecedor como formador de conhecimento para uma futura pedagoga, pois permitiu uma reflexão para a construção de uma prática educativa. (Emilia, 2018).

Esse período de estágio, serviu como uma experiência enriquecedora, que proporcionou descobertas e transformações na forma de pensar ver e agir na prática educacional nas séries iniciais do Ensino Fundamental, confrontando teorias estudadas com a pratica dentro da sala de aula. (Tarsila, 2018).

Já para Sabine, que trabalhava há quatro anos como assistente na Educação Infantil, e para Maria, que participou do Programa Institucional de Bolsas de Iniciação à Docência (PIBID) por 3 anos, sempre auxiliando professoras da Educação Infantil, o estágio nas séries iniciais do Ensino Fundamental as fez refletir sobre uma realidade ainda desconhecida e muito diferente das que vinham experienciando na Educação Infantil. Sabine, que observou as dificuldades da escola e da sala de aula nos anos iniciais, comenta que a mudança de cenário a deixou muito surpresa e, para Maria, ficou a sensação de insegurança.

Durante o período em que estive regente, percebi por diversos momentos, que existe uma falta de estrutura, tanto de recursos humanos, quanto pedagógicos dentro da sala. (Sabine, 2018).

Como trabalho no Ciei, como assistente, a mudança de cenário, foi uma das partes mais difíceis e mais importantes. Atuar em uma sala de aula foi algo surpreendente e um pouco assustador. (Sabine, 2018).

Espanto, pois a escola e a sala em que fiquei eram dificeis. Durante as observações me questionei se realmente era isso que eu queria, me senti muito insegura... eu me sinto bem mais confortável em trabalhar com as crianças da educação infantil. (Maria, 2018).

Embora Sabine e Maria, talvez por terem vivenciado mais o cenário da Educação Infantil, tenham se mostrado mais inseguras e estranhado a omplexidade do trabalho do professor nos anos iniciais do Ensino Fundamental, em outros 
relatos percebe-se que as estagiárias, apesar de identificarem várias tensões e desafios que precisarão ultrapassar ao se dedicarem à docência, e que são muitos os fatores de mal-estar, mostraram-se motivadas e entusiasmadas com a experiência do estágio e com a perspectiva de, de fato, tornarem-se professoras:

Os desafios são muitos, mas é motivador perceber que você consegue, por exemplo, ensinar uma criança ler e escrever. (Sabine, 2018).

Apesar da dificuldade, foi surpreendente e emocionante, receber bilhetinhos com frases "eu te amo, prof."; "você é linda". (Maria, 2018).

O que me motiva para a docência, é perceber que podemos fazer a diferença na vida de tantas crianças, que precisam tanto de carinho e atenção". (Maria, 2018).

A formação inicial/estágio deve contemplar a importância da afetividade entre professor e estudante. Para Hargreaves (2002), "as emoções estão no coração do ensino" e dificilmente alguém pode negar essa constatação, portanto o futuro professor precisa estar educado para a afetividade, visto que tratará com as diversidades no cotidiano escolar, e precisa saber respeitar e compreender o outro, bem como ter compreensão do inacabamento da condição humana.

Os sentimentos, mais precisamente as expressões de afetividade dos professores em relação aos alunos e vice-versa, são cruciais, pois podem ser responsáveis por mudanças de atitude como a indisciplina, o desinteresse e a desmotivação, desenvolvendo fatores de bem-estar para todos os envolvidos.

\section{CONSIDERAÇÕES FINAIS}

Apesar da carreira profissional do professor começar no seu primeiro dia de aula, como professor regente, é preciso reconhecer que o tempo vivido na universidade, durante a formação inicial, e até mesmo as suas experiências como aluno, desde a mais tenra idade, terão um impacto em suas vivências e trabalho docente.

A formação inicial, considerada a primeira etapa do processo de formação do professor, além de oferecer subsídios teóricos e práticos para o exercício da docência, deve oferecer, também, subsídios e possibilidades de reflexões sobre a realidade concreta da escola contemporânea. Além disto, conforme afirmação de Sampaio e Stobäus (2017), um dos papéis mais importante da formação inicial deve ser contribuir para a prevenção e o controle de situações de mal-estar docente, 
bem como otimizar ações para o desenvolvimento de competências necessárias para gerir situações adversas que o contexto escolar pode apresentar.

Nesse sentido, o Estágio Supervisionado, considerado uma etapa em que os futuros professores vivenciam a realidade da escola, tem também a função de, por meio da reflexão crítica, levar o futuro professor a perspectivar possibilidades para prevenir o mal-estar e construir o seu bem-estar na realização do seu trabalho. O estágio oferece vivência do "chão da escola", constituindo-se em um processo privilegiado de formação, apreensão das especificidades da profissão e produção do conhecimento a partir da leitura crítica da realidade.

Pelas narrativas das estagiárias, pode-se verificar que elas identificaram alguns dos fatores de mal-estar docente, que estão presentes em quase todas as pesquisas que tratam sobre essa temática, quais sejam: a superlotação nas salas de aula, o que aumenta o grau de indisciplina dos alunos; a falta de recursos materiais para realizar uma aula diferenciada e não ficar apenas na mesmice do quadro de giz e livro didático; a complexa relação com a família; e a inclusão de crianças com deficiências, a qual exige atenção redobrada do professor. Porém, apesar de elas terem percebido os vários desafios e a complexidade da docência, ao final do Estágio Supervisionado, mostraram-se animadas e motivadas para a profissão docente.

É importante que o futuro professor (estagiário) identifique essas dificuldades inerentes à profissão e que compreenda as complexidades da docência para que possa, a partir do estágio, dialogar com o contexto social, cultural e político existente, visando a transformá-lo.

Apesar das adversidades (existentes em qualquer profissão), a escola não deve ser encarada como um lugar de martírio. O profissional da educação deve estar preparado para enfrentar essa realidade, para que os fatores de mal-estar não venham a destruir as perspectivas positivas de sua profissão. O futuro professor deve reconhecer e saber lidar com os desafios e com as frustrações, e esses desafios devem ser compreendidos como uma alavanca motivadora para melhorar a qualidade do processo ensino-aprendizagem e o bem-estar docente. Esses desafios devem ser trabalhados, ainda, por meio de reflexão a partir da formação inicial/estágio, o que poderia resultar, também, em uma preparação profissional para as lutas políticas e pedagógicas em favor de melhorias para o ensino e em favor da valorização da docência enquanto profissão. 
A complexidade da docência: a percepção de estagiários de Pedagogia sobre os desafios para a promoção do bem-estar docente

\section{REFERÊNCIAS}

BATISTA, A. S.; ODELIUS, C. C. Infraestrutura das escolas e burnout dos professores. In: CODO, W. (Coord.). Educação: carinho e trabalho. Petrópolis: Vozes, 1999. p. 32432.

CASTRO, J. M.; REGATTIERI, M. Interação escola-familia: subsídios para práticas escolares. Brasília: UNESC/MEC, 2010.

ESTEVE, J. M. O mal-estar docente: a sala de aula e a saúde dos professores. Bauru: EDUSC, 1999.

GUERRA, M. A. S. A escola que aprende. Porto: ASA, 2000.

HARGREAVES, A.; EARL, L.; MOORE, S.; MANNING, S. Aprendendo a mudar: o ensino para além dos conteúdos e da padronização. Porto Alegre: Artmed, 2002.

JESUS, S. N. Professores sem stress: realização profissional e bem-estar docente. Porto Alegre: Mediação, 2007.

JESUS, S. N. Desmotivação e crise de identidade na profissão docente. Katálysis, Florianópolis, v. 7, n. 2, p. 192-202, 2004.

JESUS, S. N. Bem-estar dos professores: estratégias para realização e desenvolvimento profissional. Porto: Porto Editora, 1998.

KRUG, H. N.; CONCEIÇÃO, V. J. S.; KRUG, R. R.; TELLES, C. A complexidade da docência nos anos iniciais do ensino fundamental: a percepção dos acadêmicos de Educação Física em situação de Estágio Curricular Supervisionado. Revista Série-Estudos, Campo Grande, n. 39, p. 117-36, 2015.

MANTOAN, M. T. E. Inclusão escolar: O que é? Por quê? Como fazer? São Paulo: Moderna, 2003.

MARCHESI, Á. O bem-estar dos professores: competências, emoções e valores. Porto Alegre: Artmed, 2008.

MONTEIRO, R. A. Pesquisa em educação: alguns desafios da abordagem qualitativa. In: MONTEIRO, R. A. Fazendo e aprendendo pesquisa qualitativa em educação. Juiz de Fora, MG: FEME Edições, 1998.

NÓVOA, A. Professores: imagens do futuro presente. Lisboa: Educa, 2009. 
NÓVOA, A. Os professores e as histórias da sua vida. In: NÓVOA, A. (Org.). Vidas de professores. Porto: Porto Editora, 1995.

OLIVEIRA, C. B. E. de; MARINHO-ARAÚJO, C. M. A relação família-escola: intersecções e desafios. Estudos de Psicologia, Campinas, v. 27, n. 1, p. 99-108, 2010.

PIMENTA, S. G.; LIMA, M. S. L. Estágio e docência. São Paulo: Cortez, 2004.

ESCOLA MUNICIPAL IRMÃ DE LIMA MATTOS [EMILM]. Projeto Político Pedagógico [PPP]. Maracajú, MS, 2016.

RABELO, A. O. O estágio docente e a prática pedagógica no ensino público: um elo entre a teoria e a prática, a experiência e a inovação. Teoria e Prática da Educação, Maringá, PR, v. 22, n. 2, p. 182-201, 2019.

SAMPAIO, A. A.; STOBÄUS, C. D. Elementos de mal-estar docente na formação acadêmica e início da docência: potenciais fontes, consequências e estratégias de enfrentamento. Linguagens, Educação e Sociedade, Teresina, v. 22, n. 36, p. 240-63, 2017.

SCHÜTZE, F. Biography analysis on the empirical base of autobiographical narratives: How to analyse autobiographical narrative interviews-Part 1. Module B.2.1. INVITE-Biographical counseling in rehabilitative vocational training- further education curriculum, 2007. Disponível em: http://www.biographicalcounselling.com/download/B2.1.pdf; Acesso em 30/09/2008.

SCHÜTZE, F. Biography analysis on the empirical base of autobiographical narratives: How to analyse autobiographical narrative interviews-Part 2. Module B.2.2. INVITE-Biographical counseling in rehabilitative vocational training- further education curriculum, 2007. Disponível em: http://www.biographicalcounselling.com/download/B2.2.pdf; Acesso em 30/09/2008.

SILVA, M. O. E. da. Educação inclusiva - um novo paradigma de Escola. Revista Lusófona de Educação, Lisboa, v. 19, n. 19, p. 119-34, 2011.

VEENMAN, S. Perceived problems of beginning teachers. Review of Educational Research, Los Angeles, v. 54, n. 2, p. 143-78, 1984.

\section{Sobre as autoras:}

Eliane Terezinha Tulio Ferronato: Doutorado e mestrado em Educação pela Universidade Católica Dom Bosco (UCDB). Especialização em Educação Infantil pela Universidade do Estado de Mato Grosso do Sul (UEMS). Graduação 
em Pedagogia pela Universidade do Estado de Mato Grosso do Sul (UEMS). Professora da Universidade do Estado de Mato Grosso do Sul (UEMS). E-mail: eliane.ferronatto@hotmail.com, Orcid: https://orcid.org/0000-0003-2591-3386

Flavinês Rebolo: Doutorado e mestrado em Educação pela Universidade de São Paulo (USP). Graduação em Psicologia pela Universidade do Sagrado Coração (USC). Professora do Programa de Pós-Graduação em Educação da Universidade Católica Dom Bosco (UCDB). E-mail: flavines.rebolo@uol.com.br, Orcid: http://orcid.org/0000-0002-4763-7434

Recebido em: 20/05/2020

Aprovado em: 31/01/2021 
